\title{
Coronary injection ventriculography: Multiple coronary-cameral fistulas as a rare cause of stable angina pectoris
}

\author{
Umut Kocabas ${ }^{\text {a, } *}$, Esra Kaya ${ }^{b}$, Mustafa Akin ${ }^{c}$ \\ a Department of Cardiology, Soma State Hospital, Manisa, Turkey \\ b Department of Cardiology, Dogubeyazit State Hospital, Agri, Turkey \\ c Department of Cardiology, Ege University School of Medicine, Izmir, Turkey
}

\section{A R T I C L E I N F O}

\section{Article history:}

Received 19 February 2016

Received in revised form 29 February 2016

Accepted 2 March 2016

Available online 7 April 2016

\section{Keywords:}

Corono-cameral fistula

Coronary steal phenomenon

Myocardial ischemia

Stable angina pectoris

Drinking water resources

\begin{abstract}
A B S T R A C T
Coronary-cameral fistula is a rare, abnormal fistulous communication between a coronary artery and a cardiac chamber or large vessel. Being mostly asymptomatic, corona-cameral fistulas can seldom cause myocardial ischemia, congestive heart failure, arrhythmias and infective endocarditis. We represent you a case of stable angina pectoris found to have multiple corona-cameral fistulas between left coronary arteries and left ventricle in conventional coronary angiography.

(c) 2016 The Society of Cardiovascular Academy. Production and hosting by Elsevier B.V. All rights reserved. This is an open access article under the CC BY-NC-ND license (http://creativecommons.org/licenses/by-nc-nd/4.0/).
\end{abstract}

\section{Introduction}

Coronary-cameral fistula (CCF) is an abnormal fistulous communication between a coronary artery and a cardiac chamber or large vessel. $\mathrm{CCF}$ is rare and mostly diagnosed incidentally. In diagnostic coronary angiography (CAG) the incidence is reported as $0.1 \% .{ }^{1}$ Being mostly asymptomatic CCF can seldom cause myocardial ischemia, congestive heart failure, arrhythmias and infective endocarditis. ${ }^{2}$ We represent you a case of stable angina pectoris found to have multiple microfistulas between left coronary arteries and left ventricle in conventional CAG.

\section{Case}

A 65-year-old male patient referred to our outpatient clinic with chest pain and exertional dyspnea. The patient was suffering from retrosternal exertional chest pain for 6 months which relieved with rest. Previous medical history revealed hypertension and diabetes mellitus. Physical examination was normal while the electrocardiogram showed inferolateral $\mathrm{T}$ wave inversion and left ventricular hypertrophy according to Sokolow-Lyon index (Fig. A). In echocardiography, LV wall thickness were normal, left ventricle mass index was normal (LVMI:

\footnotetext{
* Corresponding author at: Department of Cardiology, Soma State Hospital, Soma, Manisa, 45500, Turkey. Tel.: + 90507997 4999; fax: +902366133202.

E-mail address: umutkocabas@hotmail.com (U. Kocabas).

Peer review under responsibility of The Society of Cardiovascular Academy.
}

$102 \mathrm{~g} / \mathrm{m}^{2}$ ) and LVEF was found 65\%. Coronary angiography was performed with an early diagnosis of coronary artery disease. There was not any significant coronary stenosis, however in late phase of contrast injection to the left coronary arteries, left ventricle filling and opacification was seen through extensive multiple microfistulas (Figs. B, C, Video 1-2-3). Due to multiple microfistulas between left coronary arteries and left ventricle, this condition was defined as "coronary injection ventriculography". Because of extensive spreading of microfistulas through left ventricle myocardium, the patient was not an appropriate candidate for surgical or transcatheter repair and regular follow up with medical therapy was planned. Symptomatic relief was provided by medical therapy with acetylsalicylic acid, ramipril, amlodipin, metoprolol and atorvastatin.

\section{Discussion}

CCFs are rare and defined as anomalous connections between coronary arteries and cardiac chambers. ${ }^{1}$ The frequency of CCF is reported as $0.1 \%$ in diagnostic CAG. ${ }^{1,3}$ Various series from Turkey showed a similar incidence of CCF as $0.08-0.11 \%{ }^{3,4}$ Being mostly asymptomatic, CCF is usually suspected by hearing a murmur in physical examination and diagnosed in further evaluation or incidentally in diagnostic CAG. Hemodynamically significant fistulas can cause symptoms like angina or dyspnea. The angina is usually associated with coronary steal phenomenon. In this phenomenon, coronary blood flow is shifted to the territory of the fistula because of the low blood pressure in diastole. As a consequence, enough blood supply cannot be provided and ischemia 


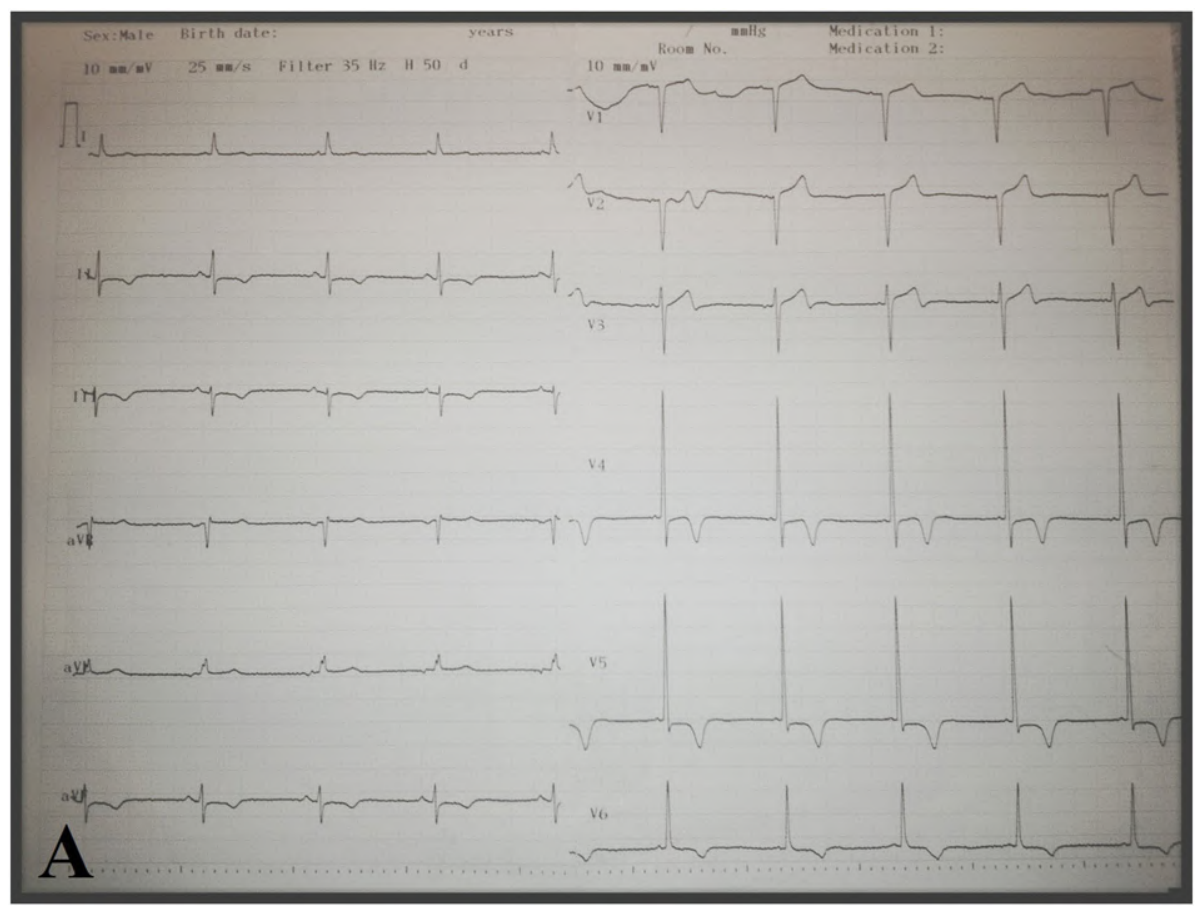

Fig. A. The twelve-lead electrocardiogram showed left ventricular hypertrophy and inferolateral T wave inversion.

occurs in the distal territory of the fistula bearing artery. ${ }^{5}$ Koh et al. showed exertional myocardial ischemia in CCF patients. ${ }^{6}$ Kiuchi et al. reported that CCFs may cause myocardial infarction due to coronary steal phenomenon. ${ }^{7}$ Complications associated with coronary artery fistulas (CAF) are myocardial ischemia, heart failure, arrhythmias, infective endocarditis, coronary thrombosis, aneurysm or rupture. ${ }^{8}$ Aging increases the risk of dilatation and/or aneurysm formation of the fistula therefore increasing the risk of complication. ${ }^{9}$ Incidence of symptoms or complications under the age of 20 is $19 \%$, which increases to $55 \%$ above the age 20 years. ${ }^{10}$ Asymptomatic and small diameter CAFs are emphasized to be followed medically. Main indications for surgical or interventional

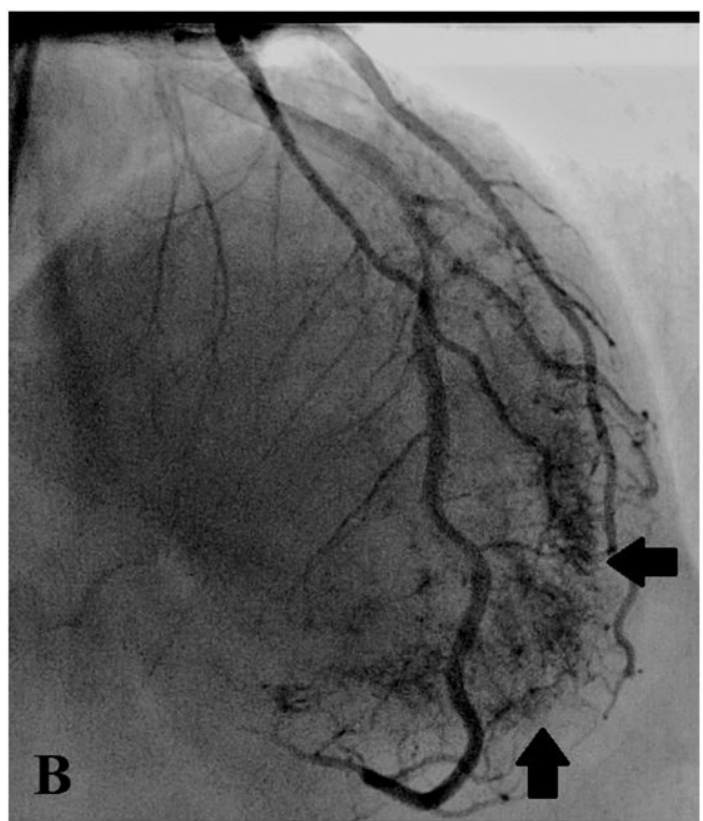

Fig. B. In late phase of contrast injection to the left coronary arteries, left ventricle opacification was seen through extensive multiple corono-cameral microfistulas (arrows). treatment of CAFs are hemodynamically important fistulas, symptomatic patient, development of myocardial infarction, heart failure, arrhythmias or infective endocarditis. ${ }^{11}$ Main purpose of treatment is the closure of fistula without damaging coronary blood flow. Surgical therapy or transcatheter coil embolization method which is currently wider in use, can be preferred. Transcatheter coil embolization method is similar to surgical therapy according to morbidity and mortality rates. ${ }^{12}$ However this method is superior to surgical therapy according to patient comfort and duration of hospitalization. Surgery is applied in patients who cannot undergo transcatheter coil embolization. In our case, due to multiple small caliber CCFs, neither surgical nor transcatheter

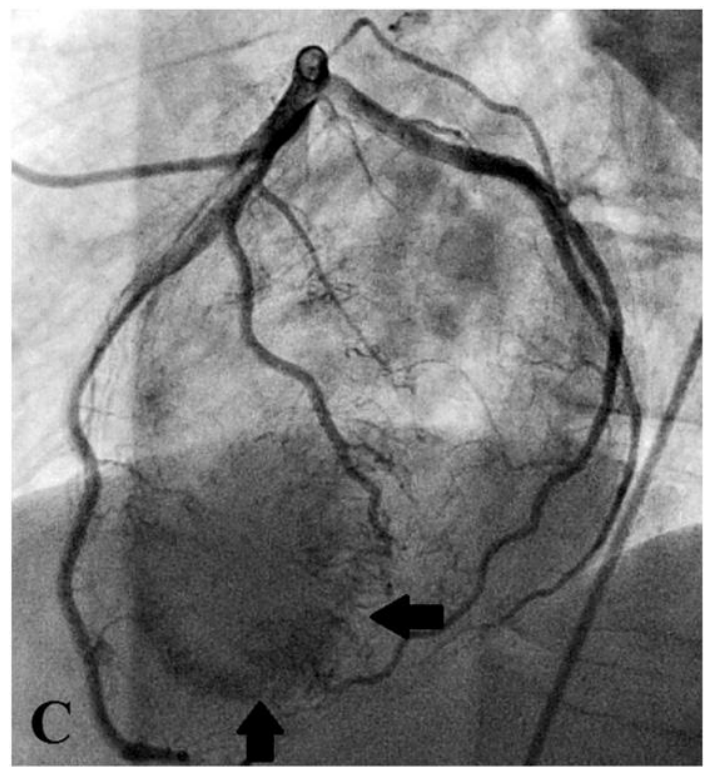

Fig. C. In late phase of contrast injection to the left coronary arteries, left ventricle opacification was seen through extensive multiple corono-cameral microfistulas (arrows). 
therapy were found appropriate and follow-up with medical therapy was planned for the patient.

\section{Conflict of interest}

There is no conflict-of-interest.

Supplementary data to this article can be found online at http://dx. doi.org/10.1016/j.ijcac.2016.03.001.

\section{References}

1. Vavuranakis M, Bush CA, Boudoulas H. Coronary artery fistulas in adults: incidence, angiographic characteristics, natural history. Catheter Cardiovasc Diagn 1995;35(2): 116-120.

2. Wolf A, Rockson SG. Myocardial ischemia and infarction due to multiple coronary-cameral fistulae: two case reports and review of the literature. Catheter Cardiovasc Diagn 1998;43(2):179-183.

3. Doğan M, Sunman H, Akyel A, et al. Prevalence and clinical features of microfistulas between the coronary artery and left ventricle: single-center experience. Turk Kardiyol Dern Ars 2014;42(4):332-338.
4. Sercelik A, Mavi A, Ayalp R, et al. Congenital coronary artery fistulas in Turkish patients undergoing diagnostic cardiac angiography. Int J Clin Pract 2003;57(4): 280-283.

5. Levin DC, Fellows KE, Abrams HL. Hemodynamically significant primary anomalies of the coronary arteries. Angiographic Asp Circ 1978;58(1):25-34

6. Koh KK, Cho SK, Kim SS. Left and right coronary artery to left ventricular fistula: demonstration of myocardial ischemia by treadmill test and Holter monitoring-a case report. Angiology 1993;44(12):977-980.

7. Kiuchi K, Nejima J, Kikuchi A, et al. Left coronary artery-left ventricular fistula with acute myocardial infarction, representing the coronary steal phenomenon: a case report. J Cardiol 1999;34(5):279-284.

8. Yuksel M, Yildiz A, Oylumlu M, Polat N, Acet H, Ozaydogdu N. Three vessel coronary cameral fistulae associated with new onset atrial fibrillation and angina pectoris. Case Rep Vasc Med 2014;2014:475325.

9. Sunder KR, Balakrishnan KG, Tharakan JA, et al. Coronary artery fistula in children and adults: a review of 25 cases with long-term observations. Int $J$ Cardiol 1997;58(1):47-53.

10. Liberthson RR, Sargar K, Berkoben JB, Weintraub RM, Levine FH. Congenital coronary arteriovenous fistula. Report of 13 patients, review of the literature and delineation of management. Circulation 1979;59(5):849-854.

11. Gowda RM, Vasavada BC, Khan IA. Coronary artery fistulas: clinical and therapeutic considerations. Int J Cardiol 2006;107(1):7-10.

12. Armsby LR, Keane CF, Sherwood MS, Forbess JM, Perry SB, Lock JE. Management of coronary artery fistula. J Am Coll Cardiol 2002;39(6):1026-1032. 